the less specific kinds are elaborated to fit the environmental situation more exactly.

Trial-and-error learning incorporates an active appetitive behaviour which constitutes the process of trial and is characterized by the retroactive action of the influence exerted by the reward. Trial-anderror learning is shown to be of immense importance in the development of bird behaviour, particularly on the effector side, in the acquisition of skill involved in the perfection of elaborate behaviour patterns, such as flight, nest-building and escaping from enemies. On the receptor side of such behaviour the conditioning element in trial-and-error learning leads to modification of the configuration of stimuli to which the animal is responding. Trial-and-error learning also serves to account for many examples of learning with puzzle-boxes and mazes. The learning function of play in improving skill is considered as a phase and is more prevalent in young birds than is usually thought. The danger of confusing maturation of an innate behaviour pattern with improvement due to trial-and-error learning is stressed.

Under this head of insight learning, Thorpe discusses the type of exploratory learning now known as latent learning, and its significance in the establishment of territory; tool using and detour behaviour are also possible examples of insight learning. In an analysis of recent work on the number concept in birds, Thorpe suggests that Kohler's conclusions that certain birds show two pre-linguistic faculties, (1) simultaneous and (2) successive, unnamed number sense, little, if at all, inferior to that of man, must be accepted as proved. The essential difference, therefore, between the number concept of animals and men is that only the latter have, in addition, the ability to deal with 'named' numbers. The significance of visual illusion experiments for the theory of insight learning is also considered, as are some other learning abilities suggestive of insight.

Analysis of the imitative abilities of birds suggests that a distinction must be made between social facilitation, local enhancement and true imitation. The first two play an important part in bird life, but the evidence for true imitation is at present very slender; vocal 'imitation' is not considered necessarily to involve imitation in the true sense.

Discussing imprinting as an innate disposition to learn in a particular direction and in a particular restricted period, it is believed that, once accomplished, this type of loarning is particularly difficult to eradicate and is significant in understanding the theory of instinctive behaviour, and especially of the innate releasive mechanism. The important evidence supplied by pathological imperfections in imprinting is examined while the perceptory side of song learning is considered as a special case of imprinting.

Some learning abilities are of doubtful significance, the most important of these being the ability to recognize individuals. The subject of tameness is also discussed, and, in Thorpe's view, genetic tameness and wildness are undoubted realities. No evidence is found for an inherited recognition of man as an enemy, but it is shown that a tendency to general wariness readily becomes attached to man, but can be overcome by a variety of learning processes.

The memory powers of birds are also considered; instances of memory for individuals extending for periods of a year or more are well authenticated, and it is possible that memory for territory is often still more enduring.

\section{MANAGEMENT PROBLEMS AND LOCAL GOVERNMENT}

$\mathrm{N}$ the most recent occasional paper of the British 1 Institute of Management, Mr. J. E. MacColl suggests that, though latent for many years, there is a crisis in local government which has been made more acute by the stresses of post-war reconstruction.

Because of this stress, there has been a trend of functions from small authorities to large, and from large authorities to the central government. From a purely administrative point of view "large local authorities are more likely to be effective instruments than small ones. For many purposes the central government may be the most effective of the lot." But in our desire to produce maximum administrative effectiveness, care must be taken not to overthrow democracy itself.' Mr. MacColl states that highly efficient local government departments are not necessarily satisfactory, and humanity, imagination and sensitiveness to local feeling are no less important than costs per head. People should not feel that their communal services are supplied from above regardless of their likes and dislikes, the ultimate test in a local democracy being whether the citizens find their town a pleasant place to live in and whether they feel responsible for what is done in their name.

Nevertheless, local government must be assessed by efficient criteria, and, in the first place, it must be acknowledged that much inefficiency has nothing at all to do with the limitations set by democratic control. In the second place, it is desirable to know what, in fact, are the costs of democracy. It is dangerously easy for councillors to ask for this return or that without any idea of what it really means in terms of extra cost. Mr. MacColl also discusses the lack of any adequate check on the number of staff in local government services. Although local government officers and especially senior officers work hard, much of their work could either be avoided or lighteried. Each extension of intensification of activity leads to a demand for more staff, who really are needed unless or until somebody starts at the beginning to recast the whole administrative scheme.

As the amount of work a local authority is called upon to do increases, more and more staff are employed, extra office space taken over and a rich variety of forms designed. There is pressure from committees to speed up output of houses or to open new branches of the public library, pressure occasionally punctuated by panic when increases of rates threaten. The process goes on without anyone asking whether the load could be carried more efficiently or shared more evenly; perhaps without anyone having a clear idea how to set about finding this out. These difficulties are accentuated by excessive departmentalization and the absence of a general manager. Although it may be disturbing to those with orthodox views of British local government, there may beneed for a hybrid political administrator to make the kind of contribution of the burgomaster or the American mayor.

Mr. MacColl also discusses the kind of men and women who are needed in local government service, and the relationships which should exist between the paid officers and the lay councillors. One of the crucial issues to be decided is whether it-is more important to have highly trained and expensive administrators, or men and women who understand the peculiarities and idiosyncrasies of their own locality.
T. H. Hawkins 